\title{
Genetic Testing of Children for Late Onset Disease
}

\section{MARY ANN SEVICK, DONNA G. NATIVIO, and TERRANCE MCCONNELL}

Sevick, Mary Ann, Nativio, Donna G. and McConnell, Terrance. "Genetic Testing of Children for Late Onset Disease," Cambridge Quarterly of Healthcare Ethics 14(1) (January 2005), pp. 47-56.

Made available courtesy of Cambridge University Press http://www.cambridge.org/

The original publication is available at http://dx.doi.org/10.1017/S0963180105050061

Over the past decade, genetic tests have become available for a wide variety of disorders. As a result we are able to predict, with some degree of certainty, whether or not an individual will develop such diseases as breast cancer, Huntington's disease, polycystic kidney disease, and familial adenomatous polyposis. The ability to predict disease poses several unique ethical considerations for clinical decisionmaking regarding the provision of genetic testing. Patients must be able to comprehend the complexities of genetic testing and the potential meaning of the results. Patients must consider the emotional, social, and economic consequences of revelations regarding their risk status. Also, obtaining information on risk status may have implications for persons other than the individual seeking genetic testing.

The decision to test children for risk of genetic disease is further complicated by the fact that, until they reach the age of majority or are deemed emancipated minors, parents must make decisions on their behalf. Children have particular developmental, social, and emotional vulnerabilities that must be considered in any decision to conduct genetic testing and/or impart results to them. Policies regarding genetic testing in children seem to vary according to whether any medical benefit is to be expected from testing. For example, population-based screening for phenylketonuria, hemoglobinopathies, and galactosemia are a routine part of pediatric care. Testing for these conditions has been shown to reduce morbidity and mortality, and there are now few ethical concerns regarding current population-based screening programs. Also, testing children for genetic conditions such as cystic fibrosis and sickle cell anemia is relatively uncontroversial as there are significant benefits to be derived from early diagnosis and medical treatment. However, genetic testing becomes more controversial when there are no or questionable medical benefits to be derived, such as in late-onset autosomal dominant diseases. Consider the case presented by Smith et al. ${ }^{1}$

Mr. Crawford's son married a woman at risk for Huntington's Disease (HD). The couple, now divorced, was married for eight years and had a son and daughter. The boy is now eight years old and the girl is six. These children are at 25 percent risk for HD. Mr. Crawford believes that the mother of his former daughter-in-law has been diagnosed with HD; the former daughter-in-law has repeatedly said that she is not interested in testing for herself. Mr. Crawford has other children and grandchildren; a widower of significant means, he has been diagnosed with inoperable cancer. He wishes to treat his grand- 
children equitably, but he believes that special needs require special commitments. He contemplates setting up a trust fund for his son's children to ensure adequate care for them should they develop HD. In order to know whether he should make these arrangements, Mr. Crawford wants to have his grandchildren tested. (p. 72)

In considering whether or not Mr. Crawford's request should be honored, a panel of coauthors in Smith et al. raised the question of whether or not children should ever be tested for HD. The majority of the panel felt that the children should not be tested, even if testing were requested by the children's parents. Their conclusions were based upon the following arguments: (1) HD is a late onset disease with high penetrance, and for which there is no known cure or treatment. Symptoms are not likely to occur until after age 30 and, thus, it is extremely difficult to see how testing is in the children's medical interest. (2) In $\mathrm{HD}$, no medical advantages are lost by waiting and allowing the children to decide for themselves whether they want to be tested. (3) Mr. Crawford may actually have wanted the test results to favor the other children in the distribution of his estate, that is, avoiding a "bad investment" in a child who carries HD. (4) Parents should be prevented from making choices that place their children at great risk, and the act of testing a child for HD is both risky and irrevocable. Knowledge of HD risk status was assumed to be harmful to the child's self-image and possibly harmful to the parent-child relationship. The panel notes that studies with adults have shown harmful consequences of testing in adults, even when the results were negative. ${ }^{2}$

\section{Paternalistic Attitudes in Arguments Regarding Refusal of Genetic Testing in Children}

To what extent is the view proposed by Smith et al. paternalistic? When we refer to paternalism in the ethics literature, we generally think in terms of the liberty-limiting principle that we may force a person to do something or that we should be able to do something to another person for that person's own good. Philosophers generally distinguish between two types of paternalism, weak and strong. Weak paternalism justifies doing something to the person without their consent and for their own good but only when the voluntariness of the person's conduct is in question-such as when the person has a serious mental defect, is ignorant, or his/her decisionmaking is otherwise impaired. Strong paternalism justifies doing something to the person without their consent or for their own good, even when the person's behavior is substantially voluntary. In other words, strong paternalism involves interfering with an agent's autonomous choices. ${ }^{3}$ When cases of paternalism are described in the literature, they usually involve some direct action, such as a procedure or test being performed because it is felt to be in the patient's best interest. However, paternalism may also refer to decisions not to take action on patients' requests, because the actions are not believed to be in their best interest.

According to Faden and Beauchamp, medicine has a long history of paternalism. ${ }^{4}$ In the interest of "doing no harm" Hippocratic writings advised physicians to "[conceal] most things from the patient....[Turn] his attention away from what is being done... and [reveal] nothing about the patient's future or present condition." Not until the 18th century were physicians encouraged 
to share information with their patients, and only then to encourage their adherence to medical care. Deception and falsehood have historically been seen as acceptable as long as the objective was to give hope to the patient. It was only in 1980 that the American Medical Association's Code of Medical Ethics was revised to include injunctions for physicians to deal honestly with patients and to respect their rights. ${ }^{5}$ In recent years, with the consumer movement of the 1970s and 1980s, and the recent focus on issues of consent in clinical studies, the autonomy model has begun to take precedence over the beneficence model. Consequently, it has become more difficult to justify cases of strong paternalism.

As the decisionmaking agent for their families, we argue that prohibiting parents from having access to genetic testing of their children for HD is like traditional definitions of strong paternalism in that others are presuming to know what is best for the family. It is unlike strong paternalism in that the freedom of the parents is being restricted for the alleged good of the children (i.e., not the parents themselves). Against this notion of quasi-strong paternalism we present the following arguments for disclosure of children's HD status to their parents based on (1) alternative explanations of the harms and benefits to the child of limited disclosure of HD status, (2) the harm of medicalizing issues of death and dying, and (3) the usefulness of a model of "constrained parental autonomy" in medical decisionmaking as it pertains to children.

In the case in question, the mother has indicated that she does not want any information about her risk status and, if she were to learn that one of her children has HD, the mother will know that she also has the disease. With this being the case one can assume that parental consent to have the children tested has not been obtained from both parents, which complicates the case somewhat. However, Smith et al. argue that, regardless of the parents' wishes, children should not be tested for HD. ${ }^{6}$ It is this conclusion that we will criticize in the paper.

\section{Harms and Benefits of Permitting Genetic Testing in Children}

\section{How Harmful Is the Truth for Parents?}

Consequentialist arguments against childhood testing for HD would include the following: (1) knowing HD status would cause harm, negatively influencing the child's self-image, causing undue anxiety, and altering normal parentchild interactions and (2) knowing HD status would provide no medical benefits for the child. Thus, testing is wrong because it involves risks with no attendant medical benefits.

Several researchers have found severe illness episodes in infancy (e.g., prematurity, low birth weight, and problems at birth) to be linked to a persistent sense of vulnerability and protectiveness on the part of the parent despite the child's obvious health. ${ }^{7}$ A major assumption in the "vulnerable child" literature is that past health events disproportionately affect maternal assessment of the subsequent health of the child and may be harmful to the child. However, more recent research does not support the persistence of the vulnerable child syndrome and has demonstrated a lack of association between health in infancy and later maternal ratings of current health in school-age children. ${ }^{8}$ Furthermore, findings of vulnerable child syndrome in families 
experiencing severe infant health events should not be generalized to families with children at risk of a late onset genetic disease. No empirical studies supporting a relationship between knowledge of a child's genetic risk and altered parenting were found in the literature. However, even if we were to assume that the population in question may be subject to vulnerable child syndrome or other unhealthy parenting behavior, we would make the following arguments. (1) All children known to be at risk of late onset genetic disease are at risk to suffer this syndrome whether they have been tested or not. Parents generally know that their child is at risk for HD, and may treat tested children no differently than untested children. (2) Parental perceptions of child vulnerability may be exacerbated in the absence of information. Not knowing the truth and being left to wonder may cause more anxiety than hearing the truth. Parents may become overvigilant, watching for each and every sign that their child is affected. (3) At least some vulnerable child syndrome cases could be avoided by providing parents with accurate information.

\section{Is Disclosure of Genetic Risk Harmful to the Child?}

Clearly, there are circumstances in which disclosing genetic risk is harmful to a child. However, as they grow, children become increasingly able to use complex reasoning, to understand death, and to imagine a future for themselves. ${ }^{9}$ Most parents are fully capable of determining where their children are in this developmental process and how and when children should be told of their risk status. Unfortunately, no empirical data exist to suggest the harms or benefits of revealing genetic risk to children or the optimal timing of disclosure.

We do know a few things about children's response to disclosure of parental illness. Barnes et al. conducted a recent qualitative study of how parents communicate with their children regarding maternal breast cancer. ${ }^{10}$ Most parents informed their children of the diagnosis, and gave the following reasons for doing so: (1) maintaining open communication was important and would help in coping with the future, (2) open communication was important for maintaining trust, and (3) open communication was expected to alleviate children's distress. Nelson et al. found that when children are told of a diagnosis of their parent's cancer, anxiety levels are lower and communication within the family is improved. ${ }^{11}$

With respect to telling children bad news about themselves, no research was found regarding disclosure of HD to children. However, studies of HIV, cancer, leukemia, and other chronic illness indicate that disclosure may be instructive. Goldman, in her work with terminally ill children, notes that children always know more than their parents think they do, and that families who maintain open communication cope most effectively when told bad news. ${ }^{12}$ In a study of long-term survivors of pediatric cancer, Slavin et al. found that good psychosocial adjustment was associated with patients' early knowledge of their diagnosis and posited that when there is no disclosure children may feel isolated, develop mistrust, and have frightening fantasies. ${ }^{13}$ We have long known that young patients with serious illness are aware of their illness and that not being told increases their anxiety. ${ }^{14}$ Children sense distress and sadness of those around them despite our efforts to behave in a normal manner and, without being told, come to understand that they are ill. 
Obviously, disclosure of a parent's or child's HD status to the child will require consideration of the developmental level of the child. A review and critique of the cognitive developmental literature addressing children's concepts of illness ${ }^{15}$ revealed that illness concept varied with developmental level, that is, Piaget's prelogical, concrete logical, and formal logical. ${ }^{16}$ There was a significant association between cognitive developmental level and understanding of illness cause and the treatment of illness. ${ }^{17}$ Less cognitively mature children conceived of illness as a moral issue and were more likely to feel they were to be blamed. ${ }^{18}$ Thus, the ability of the child to understand his or her illness will need to be considered in any discussion of genetic testing and disclosure of results.

\section{Can Healthcare Professionals Accurately Predict How People Will Respond to Bad News?}

Researchers have shown that disabled patients are less concerned with their physical disabilities than are clinicians. ${ }^{19}$ Studies have also shown clinicians to underestimate the quality of life of disabled persons. Perhaps some of the reticence to disclose HD status may be a function of the biases of clinicians toward the sick and disabled, rather than a realistic assessment of how such news will be received. We admit that some studies have shown adults to experience negative reactions to news about their HD status. However, we argue that it is unrealistic to expect such individuals to have a positive or neutral response on being told that they will develop the disease. Furthermore, one might argue that growing up with the knowledge that one has HD might be less traumatic than anxiously watching for signs year after year or trying over a period of years to deny personal risk, only to be told the unwelcome news later in life. Studies also show that some individuals experience a negative reaction to being told that they do not have the disorder. Such a negative response could be avoided altogether by early testing.

\section{Are Medical Benefits the Only Important Benefits to Be Considered?}

We argue that medical interests are not the only interests to be considered. Children have a variety of personal and economic interests, and may benefit by their parents' awareness of their HD status. In the case in question, the children with HD could clearly benefit from their grandfather's estate. Ultimately, persons affected by HD will require some form of long-term care. The longterm care system in the United States is pieced together from a variety of service providers and payer systems, and patients requiring long-term care often have a difficult time obtaining the appropriate level of care at an affordable price. Insurance coverage for homecare options such as adult day care, homecare, and respite care is virtually nonexistent. Thus, unless resources are available to pay for homecare, individuals with HD may find themselves in a nursing home long before institutionalization is absolutely necessary. On the other hand, disclosure of HD status may have negative consequences in terms of employment opportunities and the opportunity to obtain insurance coverage. Such risks are real but should be weighed against the potential economic benefits to be gained by planning for future contingencies. 
Parents can also provide appropriate guidance to their children regarding career choices that will maximize their productivity, safety, and quality of life. In the case of HD, parents may provide anticipatory guidance pertaining to career choices and encourage the development of interests and hobbies that do not require fine motor skills, enabling their children to maintain work and leisure activities after becoming symptomatic. Parents can encourage a sense of responsibility on the part of the entire family, which may benefit affected children in the form of a long-term commitment of siblings to support each other.

\section{Medical Arguments for Early Testing}

An additional consideration in support of earlier testing for late onset diseases such as Huntington's is the phenomenon of "anticipation." Anticipation, a term used to describe the tendency for age of onset of a dominantly inherited disorder to be earlier in the offspring than it was in the parent, is operative in Huntington's Disease. As many as $10 \%$ of affected individuals with HD have symptoms by age $20 .{ }^{20}$ Thus, although the typical age of onset is in middle age, it may begin at anytime between childhood and old age. ${ }^{21}$

Juvenile onset ( $<21$ years) is a variant of Huntington's Disease, some cases of which show special clinical and hereditary features. ${ }^{22}$ Marked rigidity, severe mental deterioration, pronounced motor and ceribellar symptoms, rapid decline, and epilepsy characterize early onset cases. ${ }^{23}$ Any family where the possibility of Huntington's Disease exists should be referred to a genetic professional for a pedigree analysis and detailed genetic counseling. If there is evidence of anticipation within a pedigree and the age of onset is earlier with each generation, then it is reasonable to seek a genetic diagnosis in childhood as a basis for planning for care of the child, as well as preparing other members of the family.

Finally, limiting the testing for Huntington's Disease to those over 18 ignores the fact that transmission of the defect via reproduction is possible well before that age. ${ }^{24}$ It is acknowledged in the ASHG/ACMG Report that a substantial psychosocial benefit to the competent adolescent may be a justification for genetic testing. ${ }^{25}$ Relevant issues include the impact on decisions relating to reproduction. In addition prenatal testing DNA analysis is available for fetuses at $50 \%$ risk. Fetuses at $25 \%$ risk can also be tested using linkage analysis in such a way that the genetic status of the at-risk parent is not revealed.

\section{Medicalization of Death and Dying}

Demographic and technological changes in the 20th century have resulted in death becoming a taboo subject. In former times, early death was not uncommon. People lived in constant anticipation of death, and as a result death was treated as a normal part of existence. Today's society has experienced increased longevity as a result of reductions in mortality among childbearing women, infants, and children. Mortality rates have also declined from improvements in nutrition and social and working conditions and technological advances in medicine including vaccines, antibiotics, and modern treatments such as transplants and dialysis. As a result of these changes, death is generally something that comes to individuals who have lived a reasonably long life. As a result, we 
have pushed death and dying onto the margins of our social consciousness. ${ }^{26}$ Researchers have shown that discussions of death and dying generally do not occur because physicians fear causing harm by giving bad news, lack knowledge and training on how to deliver bad news, view death as the enemy, anticipate disagreements within the family, and feel threatened by such discussions. ${ }^{27}$ Patients also contribute to lack of communication concerning issues of death and dying by actively avoiding such discussions. ${ }^{28}$

Also, because of the increasingly technological nature of medicine and the application of these technologies to those who are dying, we have relegated responsibility for dealing with death to healthcare professionals and the institutions where they work. This institutionalization of death has had several negative consequences. Efficiency requires routinization of care, which can be dehumanizing to patients and families. For the sake of quality standards and efficiency, generic plans of care are formulated for patients that are not responsive to individual circumstances. In the name of institutional efficiency, healthcare professionals often do not have the time to devote to serious discussions of illness and death, and the needs of individuals and families may not be adequately addressed. Because the driving goals behind medical care are curative, death is seen as a failure or an enemy. Consequently, death is not openly acknowledged but is, rather, pushed aside. Medical outcomes (e.g., survival, death, evidence of medical cure) are seen as the only outcomes of interest. Patient preferences, pain, quality of life, and social aspects of health and illness are not addressed in the provision of medical care.

We would argue that removing from parents the decisionmaking authority for having children tested for HD effectively reinforces the medicalization of issues of death and dying. In doing so we stifle any meaningful discourse on the subject. Healthcare professionals withhold information regarding genetic risk, family members live in fear of developing HD but fail to seek confirming tests, and families are expected to withhold information from children about their potential risk status. Medicalization of death and dying also places families at the mercy of a system that is not likely to meet their individual needs. Families and society would benefit from a family-centered approach to dealing with the question of how and when to divulged HD risk status. Under a family-centered approach, individual needs and preferences of the family can be considered. There is a greater likelihood that nonmedical needs, such as quality of life and economic well-being, will be addressed. Responsibility for discussion of death and dying can be recaptured by the family, who can address the emotional needs of individual family members better than an impersonal healthcare system. Death does not have to be seen as the enemy. It can be considered a normal part of life, an attitude that is more likely to result in a personal acceptance of one's mortality and, consequently, a "good death." Families are in a better position to handle the realities of death in a positive manner than are healthcare professionals, and can better serve as an advocate for patients in having their needs met.

\section{A Model of Constrained Parental Autonomy}

In her book Children, Families, and Health Care Decision-Making, L.F. Ross provides an alternative model for determining the appropriateness of parental judgments. ${ }^{29}$ Rather than evaluating parental decisions according to the "best 
interest" principle (in which the only outcome considered is whether the decision being made optimizes the interests of the child), she argues that a model of constrained parental autonomy is more appropriate. As surrogate decisionmakers, Ross asserts that parents cannot focus solely on the needs of the child for whom medical decisions are being made, but must consider the interests and goals of the entire family. Under this model, parents are permitted to make intrafamilial trade-offs among family members, provided that the basic needs of the child are met. ${ }^{30}$ In the case of HD, knowing the children's risk status would permit the transfer of economic assets within the family such that an affected child's future long-term care needs can be addressed, provided that the basic needs of all of their children are met.

Ross further states that parents should be allowed to make these intrafamilial trade-offs according to their own conception of the good, provided that each child's basic needs are procured. ${ }^{31}$ She points out that, given no consensus on what the good life entails, parents in a liberal society must be given great latitude in decisionmaking pertaining to the life plans for their child. Contrary to the positions taken by Smith et al., ${ }^{32}$ parents may place great value on disclosure. They may prefer to face the future head-on, rather than live in denial. They may feel that growing up with realistic expectations is far better than establishing life plans that must later be abandoned. Families may feel that knowing the truth is less anxiety provoking that living in the constant dread of discovering symptoms. Death may not be seen as the enemy.

Finally, Ross advocates great restraint on the part of institutions in scrutinizing parents and/or intervening to alter the decisions that they make pertaining to intrafamilial trade-offs, and that judicial scrutiny should be reserved for those transfers in which children serve as "donors" to those outside the intimate family. ${ }^{33}$ Parents are currently given great discretion in making medical treatment decisions for and with their children. It is difficult to see how giving them information about their child is any more harmful than, say, allowing them to consent to treatments and therapies for their children that affect their health and survival.

\section{Implications for Practice and Research}

In some circumstances, interference with parental choices is justified. Parents may not have healthy motivations for obtaining information on genetic risk, may not have the emotional stability to deal with the information, or may not be able to disclose genetic risk to their children in a sensitive manner. However, the burden of proof should be on the healthcare professional or team that is making such a judgment. We argue that, in investigating the reasonableness of a request for genetic testing, a family-centered approach should be used that recognizes the web of social relationships and contexts in which such a request is made. It is the family that will have the responsibility of guiding the child through his/her life. The family needs to be empowered to make the best choices given the circumstances of the child and the values of the family.

When disclosing bad news to children the literature instructs us to consider age and level of understanding (cognitive development, emotional adjustment, and state of health). Bad news is delivered in an unhurried manner, in private, with family/support persons present, with kindness, and by a clinician with expert knowledge of the diagnosis, treatment, and resources available. ${ }^{34}$ 
Additional research is needed regarding the manner in which children at different ages deal with bad news. Descriptive research is needed on when children born to families at known risk of HD or other late onset diseases become aware of their own risk, how they deal with this knowledge, and their expressed preferences for confirmation of their own risk status. Studies are needed to determine to what extent "vulnerable child syndrome" is present in families at known risk of late onset disorders. Descriptive studies that examine how children perceive risk and the effectiveness of different methods of disclosing risk would be useful in developing recommendations for parents regarding how and when to disclose bad news to their children. We believe that the effectiveness of different models of disclosure of children's genetic risk should be developed and evaluated.

In summary, we believe that the claim that genetic testing for adult-onset disorders should never be performed on children is oversimplified and unwarranted. In most cases, we believe that parents are fully capable of making considered choices regarding genetic testing on behalf of their children. Empirical evidence supporting the notion that disclosure of risk status will harm children and families is scanty, at best. Denying access to genetic information about their children reinforces the notion that mortality is unnatural and something that should not be talked about. It reinforces the notion that death and dying are best left to institutions, which have a fairly narrow perspective on the needs of patients and families. Parents should be able to operate under a principle of constrained autonomy, in which they are permitted to determine "the good" for their children, and in which they can make trade-offs within the family to maximize the well-being of all.

\section{Notes}

1. Smith DH, Quaid KA, Dworkin RB, Gramelspacher GP, Granbois JA, Vance GH. Early Warning: Cases and Ethical Guidance for Presymptomatic Testing in Genetic Diseases. Indianapolis: Indiana University Press; 1998.

2. See note 1, Smith et al. 1998.

3. McConnell T. Moral Issues in Health Care: An Introduction to Medical Ethics. New York: Wadsworth Publishing Company; 1997.

4. Faden RR, Beauchamp TL. A History and Theory of Informed Consent. New York: Oxford University Press; 1986.

5. See note 4, Faden, Beauchamp 1986.

6. See note 1, Smith et al. 1998.

7. Green M, Solnit AA. Reactions to the threatened loss of a child: A vulnerable child syndrome. Pediatrics 1964;34:58-66; Estroff DB, Yando R, Burke K, Snyder D. Perceptions of preschoolers' vulnerability by mothers who had delivered preterm. Journal of Pediatric Psychology 1994;19:70921; Kemper KJ, Forsyth BW, McCarthy PL. Persistent perceptions of vulnerability following neonatal jaundice. American Journal of Diseases of Children 1990;144:238-41.

8. McCormick MC, Brooks-Gunn J, Workman-Daniels K, Peckham GJ. Maternal rating of child health at school age: Does vulnerable child syndrome persist? Pediatrics 1993;92:380-8.

9. Harrison C, Kenny NP, Sidarous M, Rowell M. Bioethics for clinicians: 9. Involving children in medical decisions. Canadian Medical Association Journal 1997;156:825-8.

10. Barnes J, Kroll L, Burke O, Lee J, Jones A, Stein A. Qualitative interview study of communication between parents and children about maternal breast cancer. Western Journal of Medicine 2000;173:385-9.

11. Nelson E, Sloper P, Charlton A, While D. Children who have a parent with cancer. A pilot study. Journal of Cancer Education 1994;9:30-6.

12. Goldman A. ABC of palliative care: Special problems of children. British Medical Journal 1998;316:49-52. 


\section{Mary Ann Sevick, Donna G. Nativio, and Terrance McConnell}

13. Slavin L, O'Malley J, Koocher G, Foster D. Communication of the cancer diagnosis to pediatric patients: Impact on long-term adjustment. American Journal of Psychiatry 1982;139:179-83.

14. Spinetta J, Maloney J. Death anxiety in the outpatient leukemic child. Pediatrics 1975;56:1035-7.

15. Burbach D, Peterson L. Children's concepts of physical illness: A review and critique of the cognitive-developmental literature. Health Psychology 1986;5:307-25.

16. Bibace R, Walsh ME. Development of children's concepts of illness. Pediatrics 1980;66:912-7.

17. Carandang M, Folkins CH, Hines PA, Stewart M. The role of cognitive level and sibling illness in children's conceptualization of illness. American Journal of Orthopsychiatry 1979;49:474-81.

18. Cook S. The development of causal thinking with regard to physical illness among French children. Lawrence: University of Kansas; 1975.

19. Rothwell PM, McDowell Z, Wong CK, Dorman PJ. Doctors and patients don't agree: Cross sectional study of patients' and doctors' perceptions and assessment of disability in multiple sclerosis. British Medical Journal 1997;314:1580-3.

20. Carpenter N. Genetic anticipation. Expanding tandem repeats. Neurologic Clinics 1994;12:68397; Ridley R, Firth C, Crow T, Conneally P. Anticipation in Huntington's disease is inherited through the male line but may originate in the female. Journal of Medical Genetics 1988;25:589-95.

21. Folstein SE, Chase GA, Wahl WE, McDonnell AM, Folstein MF. Huntington disease in Maryland: Clinical aspects of racial variation. American Journal of Human Genetics 1987;41:168-79.

22. Myers R, Madden J, Teague J, Falek A. Factors related to onset age of Huntington disease. American Journal of Human Genetics 1982;34:481-8.

23. van Dijk J, van der Velde E, Roos R, Bruyn G. Juvenile Huntington Disease. Human Genetics 1986;73:235-9.

24. Bloch M, Hayden M. Opinion: Predictive testing for Huntington disease in childhood: Challenge and implications. American Journal of Human Genetics 1990;46:1-4.

25. Anonymous. Points to consider: Ethical, legal, and psychosocial implications of genetic testing in children and adolescents. American Society of Human Genetics Board of Directors, American College of Medical Genetics Board of Directors. American Journal of Human Genetics 1995;57:1233-41.

26. Ballard P. Intimations of mortality: Some sociological considerations. In: Badham P, Ballard P, eds. Facing Death: An Interdisciplinary Approach. Cardiff: University of Wales Press; 1996: Chap. 2, pp. 7-28.

27. Morrison MF. Obstacles to doctor-patient communication at the end of life. In: Steinberg MD, Younger SJ, eds. End-of-Life Decisions: A Psychological Perspective. Washington, DC: American Psychiatric Press; 1998.

28. Hinton J. An assessment of open communication between people with terminal cancer, caring relatives, and others during home care. Journal of Palliative Care 1998;14:15-23; Blackhall LJ, Murphy ST, Frank G, Michel V, Azen S. Ethnicity and attitudes toward patient autonomy. JAMA 1995;274:820-5.

29. Ross LF. Children, Families, and Health Care Decision-Making. Oxford: Clarendon Press; 1998.

30. See note 29, Ross 1998.

31. See note 29, Ross 1998.

32. See note 1 , Smith et al. 1998.

33. See note 29, Ross 1998.

34. Garwick A, Patterson J, Bennett F, Blum R. Breaking the news: How families first learn about their child's chronic condition. Archives of Pediatric and Adolescent Medicine 1995;149:991-7; Krahn GL, Hallum A, Kime C. Are there good ways to give "bad news"? Pediatrics 1993;91:578-82. 